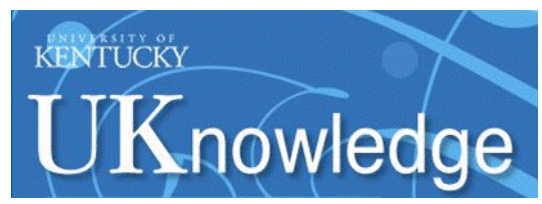

University of Kentucky

UKnowledge

3-14-2018

\title{
Application of Cross-Linked Polyborosiloxanes and Organically Modified Boron Silicate Binders in Silicon-Containing Anodes for Lithium-Ion Batteries
}

\author{
Darius A. Shariaty \\ University of Kentucky \\ Dali Qian \\ University of Kentucky, dali.qian@uky.edu \\ Yang-Tse Cheng \\ University of Kentucky, yang.t.cheng@uky.edu \\ Susan A. Odom \\ University of Kentucky, susan.odom@uky.edu
}

Follow this and additional works at: https://uknowledge.uky.edu/chemistry_facpub

Part of the Chemical Engineering Commons, and the Polymer and Organic Materials Commons Right click to open a feedback form in a new tab to let us know how this document benefits you.

\section{Repository Citation}

Shariaty, Darius A.; Qian, Dali; Cheng, Yang-Tse; and Odom, Susan A., "Application of Cross-Linked Polyborosiloxanes and Organically Modified Boron Silicate Binders in Silicon-Containing Anodes for Lithium-Ion Batteries" (2018). Chemistry Faculty Publications. 129.

https://uknowledge.uky.edu/chemistry_facpub/129

This Article is brought to you for free and open access by the Chemistry at UKnowledge. It has been accepted for inclusion in Chemistry Faculty Publications by an authorized administrator of UKnowledge. For more information, please contact UKnowledge@lsv.uky.edu. 


\title{
Application of Cross-Linked Polyborosiloxanes and Organically Modified Boron Silicate Binders in Silicon-Containing Anodes for Lithium-Ion Batteries
}

\author{
Digital Object Identifier (DOI) \\ https://doi.org/10.1149/2.0801803jes \\ Notes/Citation Information \\ Published in Journal of The Electrochemical Society, v. 165, issue 5, p. A731-A735. \\ (C) The Author(s) 2018. Published by ECS.
}

This is an open access article distributed under the terms of the Creative Commons Attribution NonCommercial No Derivatives 4.0 License (CC BY-NC-ND, http://creativecommons.org/licenses/by-nc-nd/ 4.0/), which permits non-commercial reuse, distribution, and reproduction in any medium, provided the original work is not changed in any way and is properly cited. For permission for commercial reuse, please email: oa@electrochem.org. 


\title{
Application of Cross-Linked Polyborosiloxanes and Organically Modified Boron Silicate Binders in Silicon-Containing Anodes for Lithium-Ion Batteries
}

\author{
Darius A. Shariaty, ${ }^{1}$ Dali Qian, ${ }^{2}$ Yang-Tse Cheng, $\oplus^{3}$ and Susan A. Odom $\oplus^{1, *, z}$ \\ ${ }^{1}$ Department of Chemistry, University of Kentucky, Lexington, Kentucky 40506, USA \\ ${ }^{2}$ Electron Microscopy Center, University of Kentucky, Lexington, Kentucky 40506, USA \\ ${ }^{3}$ Department of Chemical and Materials Engineering, University of Kentucky, Lexington, Kentucky 40506, USA
}

\begin{abstract}
To determine the effect of cross-linking in polymer binders on gravimetric capacity and retention in charge/discharge cycling of lithium-ion batteries containing silicon anodes, polymers with a varied chemiophysical characters have been studied as electrode binders. Here we report the utilization of cross-linked polyborosiloxanes and a boron-modified organosilicate as binders for nanoparticulate silicon-containing anodes for lithium-ion batteries. We show that highly cross-linked binders enable a large degree of capacity to be accessed and that capacity retention is greater when the electrodes are cycled in half cells. More extensive analysis of the boron-modified organosilicate is further explored.

(C) The Author(s) 2018. Published by ECS. This is an open access article distributed under the terms of the Creative Commons Attribution Non-Commercial No Derivatives 4.0 License (CC BY-NC-ND, http://creativecommons.org/licenses/by-nc-nd/4.0/), which permits non-commercial reuse, distribution, and reproduction in any medium, provided the original work is not changed in any way and is properly cited. For permission for commercial reuse, please email: oa@electrochem.org. [DOI: 10.1149/2.0801803jes]
\end{abstract}

(cc) BY-NC-ND

Manuscript submitted November 29, 2017; revised manuscript received February 19, 2018. Published March 14, 2018.

An increase in demand for energy storage devices with high energy and power densities has motivated researchers to investigate new electrode materials for rechargeable battery technologies. Lithium-ion batteries (LIBs) are preferred for many portable applications due to their high operating voltages, high energy densities, and long cycle lifetimes compared to more traditional battery chemistries such as lead-acid and nickel metal hydride. ${ }^{1}$ In efforts to increase the energy density of LIBs, new electrode materials have been sought to replace the graphitic anodes utilized in commercial cells. ${ }^{2}$ One of the most widely studied candidates to date is silicon $(\mathrm{Si})$, which possesses a theoretical specific capacity ( $3579 \mathrm{mAh} / \mathrm{g}$ for $\mathrm{Li}_{15} \mathrm{Si}_{4}$ ), approximately $10 \mathrm{x}$ higher than that of graphite $\left(372 \mathrm{mAh} / \mathrm{g}\right.$ for $\left.\mathrm{LiC}_{6}\right) .{ }^{1}$ However, tailored strategies must be designed to accommodate the inherent $300 \%$ volume expansion of Si upon full lithiation, which causes Si to disintegrate. ${ }^{3-5}$

A variety of tactics have been employed to prevent the severe capacity loss of Si-based anodes during cycling, which include lowering particle sizes and/or varying the shapes of Si-containing materials to minimize pulverization and/or excessive solid-electrolyte interphase (SEI) formation. Among particulates, Si nanoparticles (SiNPs) below $\sim 150 \mathrm{~nm}$ in diameter tend to survive the alloying process, whereas those above this critical limit tend to fracture. ${ }^{5}$ For example, Cui and co-workers have reported a variety of $\mathrm{Si}$ architectures that lead to enhanced capacity retention in Li half cells. ${ }^{6}$ By limiting the particle size and weight percent, researchers at Argonne National Laboratory demonstrated improvements in capacity retention when SiNPcontaining electrodes were cycled in full cells. ${ }^{7-9}$

Another approach to extending the cycling lifetimes of $\mathrm{Si}$ containing anodes is to modify the chemiophysical characteristics of the polymer binder to encourage stronger interactions with the polar and functionalizable $\mathrm{SiO}_{2}$ and $\mathrm{Si}-\mathrm{OH}$ surfaces of SiNPs. ${ }^{10-13}$ Compared to the more traditionally utilized binder poly(vinylidene difluoride), which contains no labile functional groups, the sodium salts of Nafion, ${ }^{14}$ polyacrylic acid, ${ }^{15}$ and carboxymethyl cellulose, ${ }^{16}$ as well as combinations of polymers, ${ }^{17,18}$ have been utilized in anodes with greater success. Additionally, surface-functionalization, ${ }^{19}$ entrapping in situ polymerization, and cross-linking polymers have proved efficacious in improving capacity retention. ${ }^{20-24}$

In considering new polymer binders for evaluation in silicon anodes, we sought a polymer with components that would favorably interact with the silicon particle surface, whether elemental silicon or a silicon oxide. Furthermore, we preferred a tailorable polymer that could be prepared in ambient conditions. Finally, we required that any binder be low cost and scalable. Siloxane-containing polymers seem to satisfy many of these requirements. Polyborosiloxane (PBS) binders have the potential for favorable interactions with $\mathrm{SiO}$ or $\mathrm{SiO}_{2}$ surfaces through dipole-dipole interactions, which could serve as a route to adhere the binder to the surface of Si particles. ${ }^{25,26}$ In 2016 a polysiloxane was cross-linked in an in situ reaction post polymerization, which was conducted under nitrogen atmosphere; resultant electrodes containing this binder displayed greater capacity retention than the linear binders to which it was compared. ${ }^{27}$ Seeking to conduct polymer binder synthesis in ambient atmosphere, rather than using an air-sensive radical polymerization, we chose to investigate condensation polymerizations - the same reaction typically utilized in PBS synthesis.

In addition to the potential for greater interactions between the surface and binder, the diversity of cross-linking and functionalization in this class of polymers allows for additional handles that could be used to modify polymer properties. Depending on the degree of cross-linking, which can be modified with cross-linking agents, the mechanical properties of these polymers range from viscoelastic to rigid, ${ }^{28-30}$ offering the potential to conduct studies on the relationship of mechanical properties and cycling performance. PBSs present additional characteristics consistent with requirements for effective binders in LIB electrodes. While electrically insulating as neat materials, silicone rubbers can be made electronically conductive when blended with materials such as carbon black (CB). ${ }^{31}$ Furthermore, the modification of silicones with neutral boron-containing compounds enables high lithium-ion conductivity in solid systems. ${ }^{32,33}$ Additionally, PBS binders are attractive due to the self-healing properties. ${ }^{30,34,35}$

Here, we report the utilization of cross-linked PBSs as binders in a nanoparticulate silicon anode, where the polymers are partially cross-linked in their initial synthesis and further cross-linked during curing of the electrode slurry. We show that highly cross-linked PBS and boron-modified organosilicate binders allow for a large degree of capacity to be accessed in the anode and that capacity retention is greater when cycled in half cells. A more thorough analysis of the boron-modified organosilicate, or ormosil, binder is presented.

\section{Experimental}

Materials.-Dichlorodimethylsilane $(99 \%)$, boric acid $\left(\mathrm{B}(\mathrm{OH})_{3}\right.$, 99.99\%), and triethoxyphenylsilane (TEPS, 98\%) were purchased from Alfa Aesar. Diglyme ( $>99.0 \%$, no inhibitor) was purchased 
from TCI. Ethanol (EtOH) and dichloromethane (DCM, ACS grade) were purchased from Macron. Tetrahydrofuran (THF, 99.5\%) was purchased from Acros Organics. Silicon nanoparticles of 30-50 nm average particle size were purchased from Nanoamor. Super65 carbon black was purchased from Timical. Battery grade $\mathrm{LiPF}_{6}$, ethylene carbonate (EC), ethyl methylcarbonate (EMC), and fluoroethylene carbonate (FEC) were purchased from BASF.

Preparation of polysiloxane binder (Polymer 1).Dichlorodimethylsilane $(95 \mathrm{~mL})$ was combined with DCM $(180 \mathrm{~mL})$ in a $500 \mathrm{~mL}$ round-bottomed flask, which was immersed in an ice bath. To the flask, ultrapure Millipore water $(180 \mathrm{~mL})$ was added dropwise over $30 \mathrm{~min}$. Concentrated aqueous sodium carbonate $(100 \mathrm{~mL})$ was then added dropwise to partially neutralize the solution. The resulting two-phase solution was separated, reserving the organic layer. Extractions with DCM $(3 \times 20 \mathrm{~mL})$ were performed to gather the siloxane condensates. The extracts were combined with the previously reserved organic phase. The organic materials were then combined in a separatory funnel, and the organic layer was washed with concentrated sodium carbonate $(2 \times 50 \mathrm{~mL})$, followed by washing with water $(2 \times 50 \mathrm{~mL})$. The organic layer was isolated and filtered through a medium fritted funnel, then concentrated by rotary evaporation. The isolated oil was dried in a vacuum oven at $60^{\circ} \mathrm{C}$ overnight.

Preparation of cross-linked polyborosiloxane binders (Polymers 2-4).-Polymer $1, \mathrm{~B}(\mathrm{OH})_{3}$, and TEPS were added to a $50 \mathrm{~mL}$ conical flask containing a large stir bar, and the flask was immersed in a sand bath that was brought to $190^{\circ} \mathrm{C}$ over $1 \mathrm{~h}$, then held at that temperature for $14 \mathrm{~h}$, all conducted open to air. The resulting solid was dissolved in hexanes, filtered, and concentrated by rotary evaporation, then dried in a vacuum oven at $70^{\circ} \mathrm{C}$ overnight.

$$
\begin{aligned}
& \text { Polymer 2. } 2.858 \mathrm{~g} \text { Polymer } 1,0.157 \mathrm{~g} \mathrm{~B}(\mathrm{OH})_{3}, 0.171 \mathrm{~g} \text { TEPS. } \\
& \text { Yield : } 1.812 \mathrm{~g}(56.8 \%) \text {. }
\end{aligned}
$$

Polymer 3. 2.086 g Polymer 1, $0.261 \mathrm{~g} \mathrm{~B}(\mathrm{OH})_{3}, 0.267 \mathrm{~g}$ TEPS.

Yield : $1.446 \mathrm{~g}(55.3 \%)$.

Polymer 4. $1.363 \mathrm{~g}$ Polymer $1,0.544 \mathrm{~g} \mathrm{~B}(\mathrm{OH})_{3}, 0.814 \mathrm{~g}$ TEPS.

Yield : $1.619 \mathrm{~g}(59.5 \%)$.

Preparation of ormosil binder (Polymer 5).- $\mathrm{B}(\mathrm{OH})_{3}(0.894 \mathrm{~g}$, $14.5 \mathrm{mmol}$ ) was combined with TEPS (3.48 g, $14.5 \mathrm{mmol})$ in a $50 \mathrm{~mL}$ conical flask. EtOH (4 mL) was added, and the reaction flask was immersed in a sand bath, which was raised to $150^{\circ} \mathrm{C}$ over the course of $2 \mathrm{~h}$, then held at this temperature for an additional $24 \mathrm{~h}$. Dissolution of $\mathrm{B}(\mathrm{OH})_{3}$ was noted at $120^{\circ} \mathrm{C}$, followed by solidification at $130^{\circ} \mathrm{C}$. After removing the reaction flask from the oil bath, the solid product was stored in the reaction flask for one day at ambient temperature after which THF $(50 \mathrm{~mL})$ was added. The solvent penetrated the solid resin as the temperature was slowly brought to $150^{\circ} \mathrm{C}$ by again immersing the flask in the sand bath during which time the solvent evaporated, over $\sim 2 \mathrm{~h}$. The temperature was raised to $190^{\circ} \mathrm{C}$ over $4 \mathrm{~h}$. The final material was dissolved in THF $(\sim 50 \mathrm{~mL})$, and solids were removed by filtration through a coarse fritted funnel. The product, a white solid, was stored as a $7.14 \mathrm{wt} \%$ solution in THF.

Electrode preparation.-Slurries were composed of a 3:1:1 mass ratio of SiNPs:carbon black:binder, where diglyme was used as the dispersive solvent. Homogenous suspensions of the above were prepared in scintillation vials where the suspension was magnetically stirred for $5 \mathrm{~h}$ in conjunction with periodic sonication $(3 \times 5 \mathrm{~min})$. This suspension was cast onto copper foil and was spread with a doctor blade set at $50 \mu \mathrm{m}$, then was allowed to dry for $24 \mathrm{~h}$ in ambient conditions, after which it was cured in vacuum oven at $135^{\circ} \mathrm{C}$ for $24 \mathrm{~h}$.
Electrodes were punched by $14 \mathrm{~mm}$ die-cut lever press and immediately transferred to an argon-filled glove box. This material was brittle and did not allow stable casting thicknesses above $\sim 100 \mu \mathrm{m}$.

Half-cell construction.-2032 coin cells were constructed in an argon-filled glove box $\left(\mathrm{H}_{2} \mathrm{O}\right.$ and $\mathrm{O}_{2}$ levels below $\left.1.5 \mathrm{ppm}\right)$ using 9/16" inch discs of lithium (Sigma-Aldrich), 10/16" inch PP/PE/PP trilayer Celgard separators, and stainless steel coin cell parts. Electrolyte

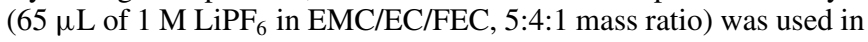
each half cell.

Constant-Rate cycling protocol.-Following construction, the electrolyte was allowed to wet the half cells over $2 \mathrm{~h}$ prior to cycling. These were then cycled using a Landt CT2001A cycler, voltage window of $0.01 \mathrm{~V}$ to $1.5 \mathrm{~V}$, with a rest time of 5 min allowed between charge and discharge. A current range of 167-169 $\mu$ A was used, determined based on the capacity of the cell using only the mass of silicon (assumed to be $60 \%$ of final electrode mass) at a theoretical capacity of $3000 \mathrm{mAh} / \mathrm{g}$.

Variable-Rate cycling protocol.-After an initial $2 \mathrm{~h}$ wetting/resting period, half cells were initially cycled at $\mathrm{C} / 20$ rates for five cycles prior to performing a rate-step experiment. Following these first 5 cycles, cycling was conducted for 3 cycles each at the following rates: $\mathrm{C} / 10, \mathrm{C} / 5, \mathrm{C} / 2, \mathrm{C}, 2 \mathrm{C}$, and finally back to $\mathrm{C} / 10$.

Characterization.-Optical microscope images were recorded on a Nikon ECLIPSE 55i microscope. Samples were prepared after letting the polymer dry in ambient conditions on a glass slide. While not shown, images of polymers dried at room temperature in a vacuum oven between two glass slides were essentially equivalent. SEM images were obtained using a Hitachi S-4300 field-emission instrument using an accelerating voltage of $10 \mathrm{kV}$ in secondary mode. Samples were obtained by disassembling the coin cells, washing electrodes with DCM, and then storing them in a glove bag under argon. The samples were exposed to air for $<20 \mathrm{~s}$ in their transfer from the glove bag into the SEM chamber. IR spectra were obtained from a Thermo-Scientific Nicolet 6700 FT-IR equipped with a smart iTR diamond-attenuated total reflectance sampling accessory, using 25 scans.

\section{Results and Discussion}

Polysiloxane (Figure 1) was prepared in house by reaction of dichlorodimethylsilane with water in dichloromethane, with concentrated aqueous sodium carbonate added to partially neutralize the solution. The resultant polymer was used to create cross-linked PBSs using both $\mathrm{B}(\mathrm{OH})_{3}$ and TEPS (Figure 1) as cross-linkers (Table I, entries 2-4). A variety of chemical reactions could lead to crosslinking: (1) the condensation of $\mathrm{Si}-\mathrm{OH}$ groups end-capping the linear polysiloxanes with $\mathrm{B}-\mathrm{OH}$ groups, forming $\mathrm{B}-\mathrm{O}-\mathrm{Si}$ bridges and releasing water, (2) the condensation of $\mathrm{Si}-\mathrm{OH}$ groups end-capping the linear polysiloxanes with $\mathrm{Si}-\mathrm{OEt}$ groups, forming $\mathrm{Si}-\mathrm{O}-\mathrm{Si}$ bridges and releasing ethanol, and (3) the condensation of $\mathrm{Si}-\mathrm{OH}$ groups end-capping the linear polysiloxanes with $\mathrm{Si}-\mathrm{OH}$ groups formed by

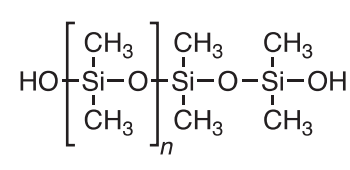

polysiloxane

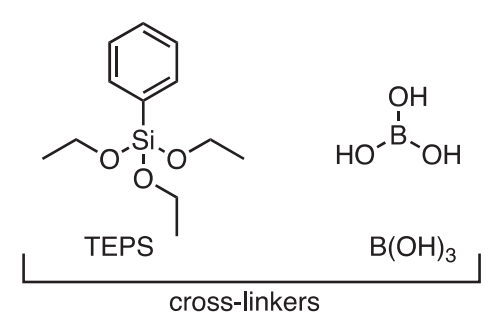

cross-linkers
Figure 1. Representations of the chemical structures of linear polysiloxane and the cross-linkers triethoxyphenylsilane (TEPS) and boric acid $\left(\mathrm{B}(\mathrm{OH})_{3}\right)$. 
Table I. Composition of polymer binders examined in this study.

\begin{tabular}{cccc} 
Polymer & polysiloxane $(\mathrm{wt} \%)$ & $\mathrm{B}(\mathrm{OH})_{3}(\mathrm{wt} \%)$ & TEPS $(\mathrm{wt} \%)$ \\
\hline 1 & 100 & - & - \\
2 & 90 & 5 & 5 \\
3 & 80 & 10 & 10 \\
4 & 50 & 20 & 30 \\
5 & - & 80 & 20
\end{tabular}

hydrolyzed Si-OEt groups in TEPS/B $(\mathrm{OH})_{3}$, forming Si-O-Si bridges and releasing water. In one case, the linear polymer was not utilized: Only $\mathrm{B}(\mathrm{OH})_{3}$ and TEPS were combined (Table I, entry 5). In this latter case, the material is better described as a boron-modified ormosil - an organically modified silicate. Note that in this case, the weight ratio was equivalent to a $1: 1$ molar ratio of $\mathrm{B}(\mathrm{OH})_{3}$ :TEPS.

In all cases, the prepared polymers were combined with SiNPs and carbon black in a 1:3:1 weight ratio and dispersed into diglyme before casting onto copper foils to prepare electrode films. Electrodes were cured in a vacuum oven at 130 to $140^{\circ} \mathrm{C}$ for 16 to $24 \mathrm{~h}$. Half cells were prepared by pairing 9/16" lithium discs with 10/16" punched SiNP electrode films in 2320 coin cells containing a $1 \mathrm{M}$ solution of $\mathrm{LiPF}_{6}$ in $\mathrm{EMC} / \mathrm{EC} / \mathrm{FEC}$ (5:4:1) as the electrolyte. Prior to cycling, all cells were given a $2 \mathrm{~h}$ rest period. Cycling was performed at a rate of $\mathrm{C} / 10$, which was calculated assuming that the final mass of the electrodes contained the original 1:3:1 mass ratio of polymer:SiNPs:carbon black.

Charge capacities and columbic efficiencies for the first hundred cycles are shown in Figure 2. For the linear polysiloxane (1) and the least cross-linked PBSs ( 2 and $\mathbf{3}$ ), the initial capacities were the lowest. The capacity of the electrode containing the linear polymer 1 faded rapidly, and after fewer than 10 cycles, the capacities of the electrodes containing cross-linked polymers $\mathbf{2}$ and $\mathbf{3}$ fell below
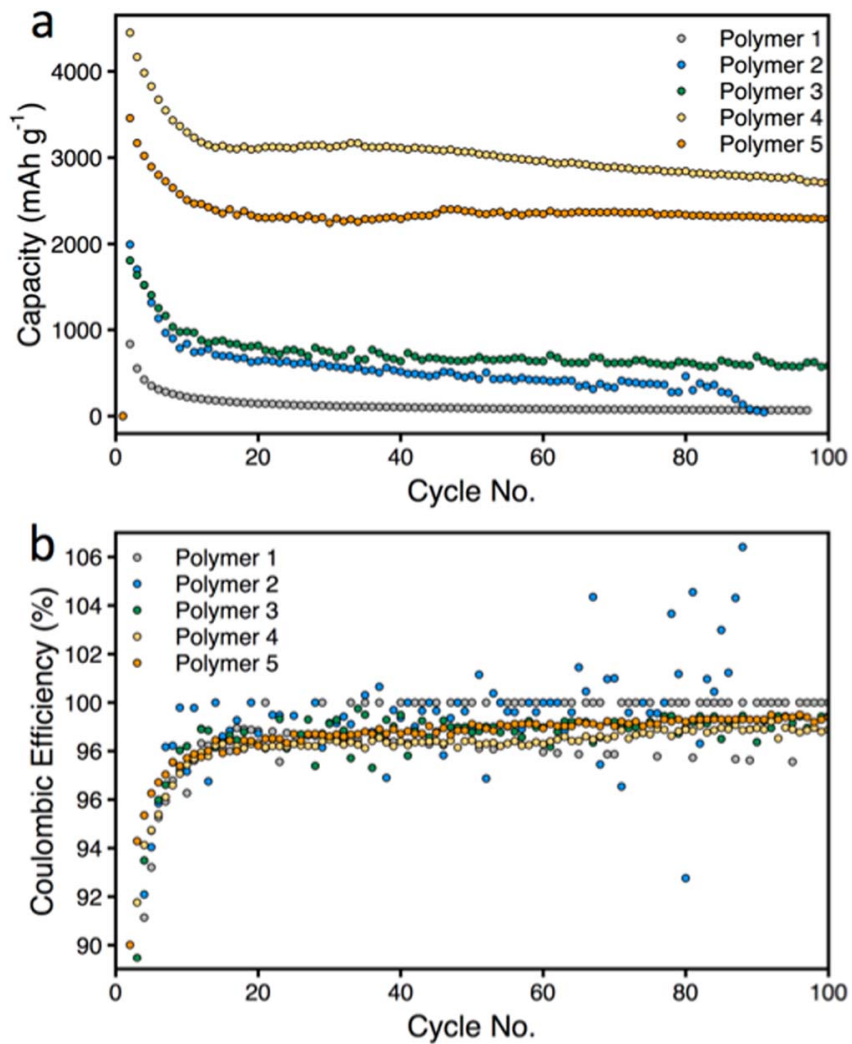

Figure 2. Charge capacities (a) and coulombic efficiencies (b) of Li half cells with a Si-containing electrodes comprised of 1:3:1 ratio of binder:SiNP:carbon black, cycled at a rate of $\mathrm{C} / 10$.

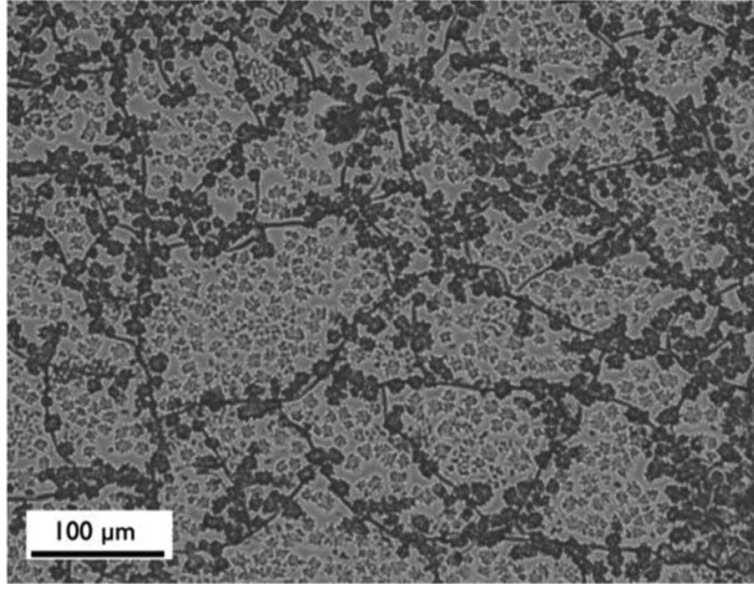

Figure 3. An optical microscope image of a film of polymer $\mathbf{5}$ after allowing it to dry following casting from a solution in tetrahydrofuran.

$1000 \mathrm{mAh} \mathrm{g}^{-1}$. The more highly cross-linked PBS (4) showed the highest capacity initially, which dropped to just under $3000 \mathrm{mAh} \mathrm{g}^{-1}$ at one hundred cycles. Intriguingly, the cross-linked ormosil binder (5) showed little capacity fade, which started at around cycle 20. Additionally, its coulombic efficiency continued to rise as cycling progressed. These results motivated us to pursue further analysis of polymer $\mathbf{5}$.

Again, polymer 5 is simply a combination of $\mathrm{B}(\mathrm{OH})_{3}$ and TEPS in a 1:1 molar ratio, which is prepared by heating the two reactants in ethanol. Unlike the PBSs, which are transparent or translucent colorless resins, the ormosil is a white solid with no apparent flowable characteristics. As prepared, we presume polymer $\mathbf{5}$ to be a collection of oligomers and polymers with a wide distribution of molecular weights, where solid-state synthesis prevents complete condensation of Si-OH and $\mathrm{B}-\mathrm{OH}$ groups. A high degree of cross-linking is considered to retard the viscoelastic flow normally associated with this class of materials, which was evidenced by a lack of apparent macroscopic flow over several days. Under optical microscope, thin films of PBS-11 deposited on microscope slides demonstrated crack-filling over day-long time scales (Figure 3), but complete homogenization of the material was never achieved.

IR spectroscopy of polymer $\mathbf{5}$ was performed to determine if expected bonds were present. The peaks in the IR spectrum (Figure 4) are consistent with the positions of expected functional groups. The intense peaks spanning ca. $1000-1150 \mathrm{~cm}^{-1}$ are consistent with $\mathrm{Si}$ $\mathrm{O}-\mathrm{Si}$ and B-O-H in-plane bending, expected at $1130-1000 \mathrm{~cm}^{-1}$ and $1150 \mathrm{~cm}^{-1}$. A strong peak spanning ca. 1300 to $1500 \mathrm{~cm}^{-1}$ with

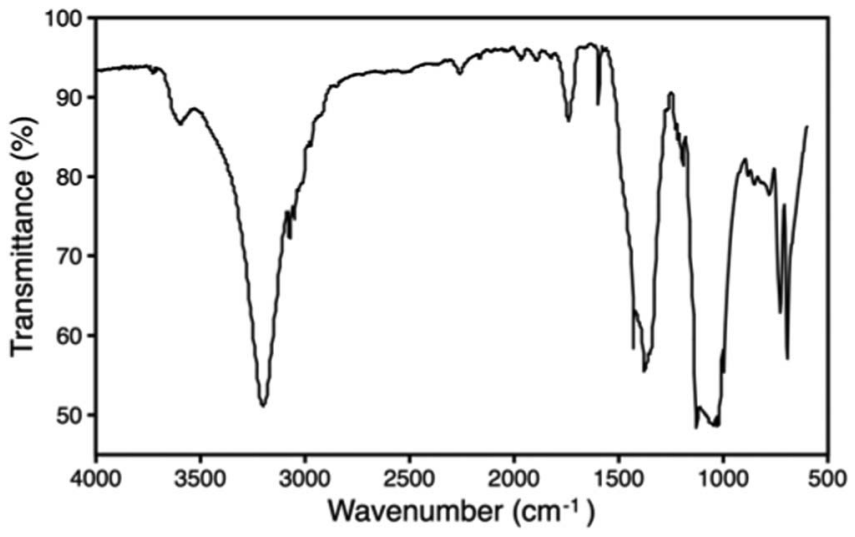

Figure 4. Infrared spectrum of polymer 5, resulting from the reaction of $\mathrm{B}(\mathrm{OH})_{3}$ and TEPS in a $1: 1$ molar ratio. 

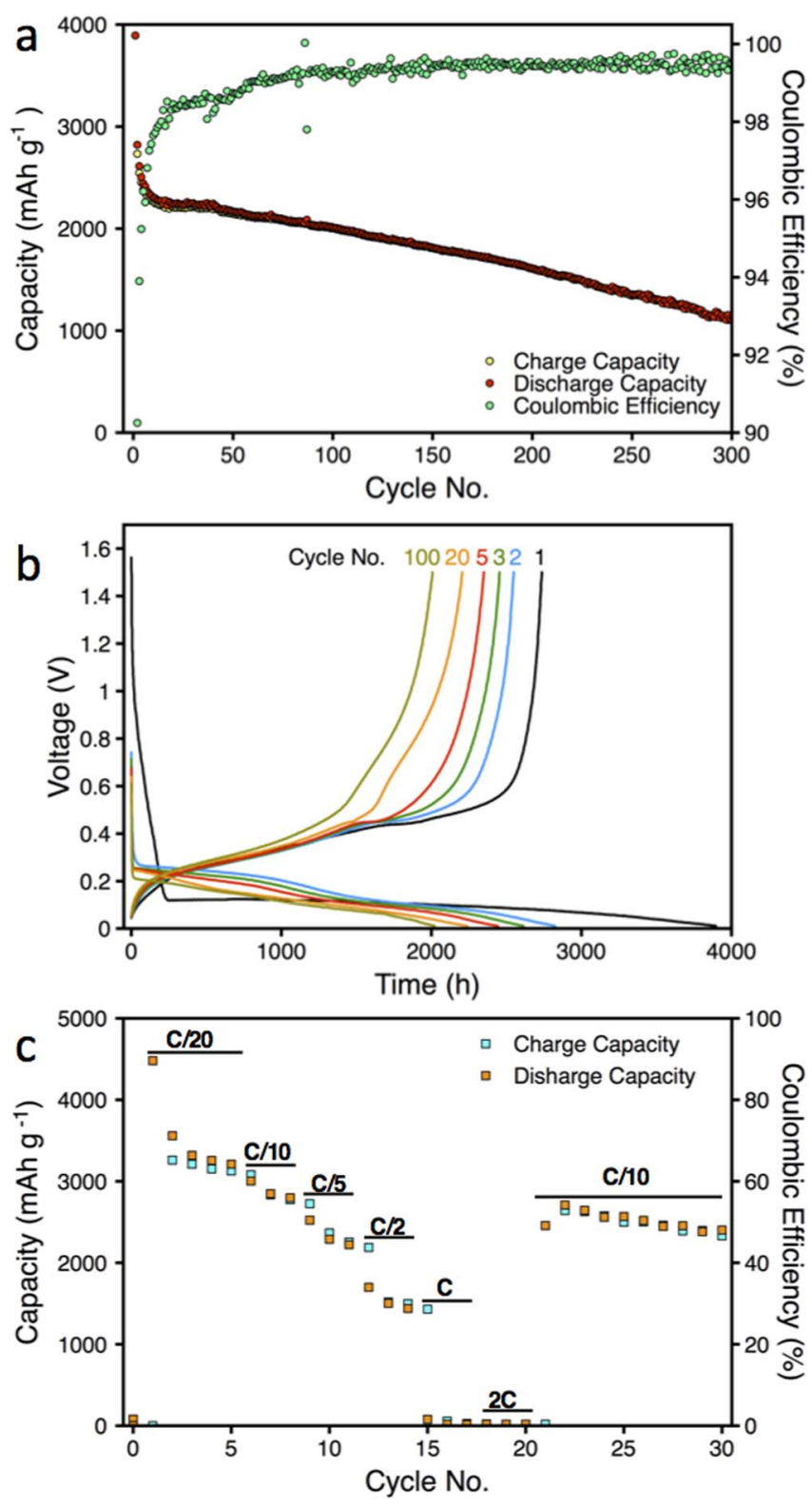

Figure 5. (a) Charge and discharge capacity of a Li half cell containing SiNP electrodes with a 1:3:1 ratio of carbon black:SiNP:polymer in which the polymer is polymer $\mathbf{5}$, and coulombic efficiency for each cycle. (b) Voltage vs. capacity plots for the cell from plot (a). (c) Rate study for an equivalent electrode in a Li half cells with five cycles at $\mathrm{C} / 20$, then three cycles each at $\mathrm{C} / 10$, $\mathrm{C} / 5, \mathrm{C} / 2, \mathrm{C}$, and $2 \mathrm{C}$, then ten cycles at $\mathrm{C} / 10$.

maximum intensity at $1375 \mathrm{~cm}^{-1}$ may contain Si-O-B and B-O-B moieties, expected at $1340 \mathrm{~cm}^{-1}$ and $1380 \mathrm{~cm}^{-1}$, respectively. The less intense peak at $1740 \mathrm{~cm}^{-1}$ is consistent with the position of $\mathrm{C}=\mathrm{C}$ bending in an aromatic ring, and the sharp peaks between 3000 and $3100 \mathrm{~cm}^{-1}$ are consistent with the position of aromatic $\mathrm{C}-\mathrm{H}$ stretches, both of which are expected if phenyl rings are present. The small peaks just below $3000 \mathrm{~cm}^{-1}$ could arise from $\mathrm{sp}^{3}$-hybridized $\mathrm{C}-\mathrm{H}$ stretches from residual ethoxy groups. Finally, the intense broad peak centered at ca. $3200 \mathrm{~cm}^{-1}$ is consistent with $\mathrm{O}-\mathrm{H}$ stretches that would arise from a B-O-H arrangement; other peaks at $3200 \mathrm{~cm}^{-1}$ and may arise from $\mathrm{O}-\mathrm{H}$ stretches such as that from Si-O-H and $\mathrm{H}_{2} \mathrm{O}$.

Further cycling of polymer $\mathbf{5}$ in lithium half cells showed some variability in the initial capacity of the Si-based electrode. A representative example of cycling performance of electrodes containing polymer $\mathbf{5}$ at a rate of $\mathrm{C} / 10$ is shown in Figure 5a. Cycling data show

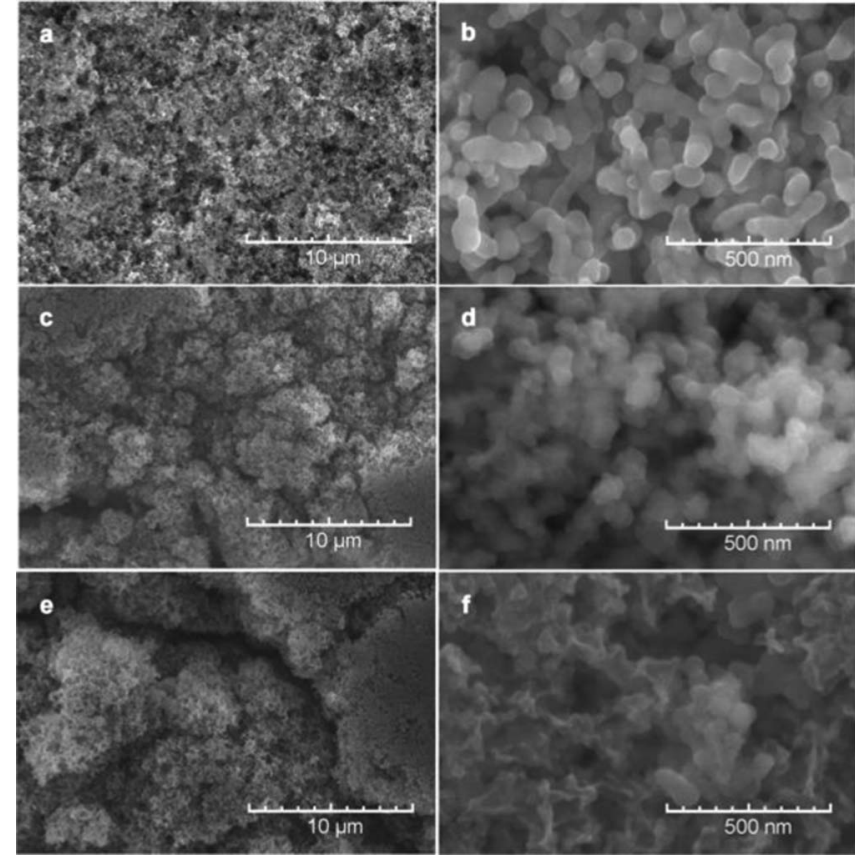

Figure 6. SEM images of the final electrode material prior to cycling (a,b). SEM images of a post-cycled electrode taken from the C/20 rate study, following 35 charge/discharge cycles (c,d). SEM images of an electrode of the same composition cycled at a rate of $\mathrm{C} / 10$ for over 300 cycles $(\mathrm{e}, \mathrm{f})$.

the achievement of $99 \%$ coulombic efficiency after $\sim 10$ cycles following rapid initial capacity loss. This initial irreversible capacity loss is likely associated with the consumption of residual hydroxyl groups present in the binder, as well as loss of contact with a portion of the active material, and the high capacity retention observed is associated with three-dimensional network that encases CB and SiNPs, keeping them in close contact. In the voltage vs. time profiles shown in Figure $5 b$, a striking preservation of capacity is observed. Results from multiple coin cells show similar capacity values and trends in fade. A rate study was performed as shown in Figure 5c. First, half cells were cycled at a rate of $\mathrm{C} / 20$ for five cycles to allow for the stable SEI formation. Following these first five cycles, the cells were charged and discharged for three cycles each at rates $\mathrm{C} / 10, \mathrm{C} / 5, \mathrm{C} / 2$, $\mathrm{C}$, and $2 \mathrm{C}$, after which ten $\mathrm{C} / 10$ cycles were completed. After a decline in capacity for the faster charge/discharge cycles, cell capacity rises when returned to the $\mathrm{C} / 10$ rate.

SEM images (Figure 6) of the pre-cycled electrode also agree with polymer 5 having an oligomeric three-dimensional structure, which is supported by features observed at magnification imaging, including the electrode's high porosity and the presence of a thin coating on the particles. Following cycling, disassociation of carbon particles from SiNPs is evident, which increased with further cycling. Cracking was observed under all post-cycling circumstances. Intriguing, too, is the gradual 'flattening' of the bulk electrode material, as seen in the differences among the electrodes with no cycling, 35 cycles, and 300+ cycles. The electrode is in fact smoother after cycling, which may be due to loss of active materials from the high-porosity electrode surface. These morphological changes, coupled with deposition of material on the side of the separator facing SiNPs, elucidate electrode material separation as a potential mechanism for the initial capacity loss seen in Figure 5.

\section{Conclusions}

In this study, highly cross-linked PBSs and an ormosil binder employed in a $60 \mathrm{wt} \%$ SiNP anode allowed for excellent capacity retention. Further analysis of the ormosil binder shows evidence of 
cross-linking reactions and robust capacity retention in lithium half cells. The cyclability of this electrode is attributed to the functional groups employed, which may be considered not only a logical, but necessary, property for the stable function of an electrode with significant volume expansion and contraction. To address initial capacity loss and electrode viability, future studies will involve cycling in full cells as well as further analysis of the effect of the degree of crosslinking and functional group identity on binder mechanical properties and cycling performance.

\section{Acknowledgments}

We thank the National Science Foundation for Award No. 1355438 (EPSCoR: Powering the Kentucky Bioeconomy for a Sustainable Future). We thank Celgard for their donation of battery separators. We thank Matthew Casselman and Bryant Polzin for helpful discussions.

\section{ORCID}

Yang-Tse Cheng (D) https://orcid.org/0000-0003-0737-9212

Susan A. Odom (1D https://orcid.org/0000-0001-6708-5852

\section{References}

1. G. E. Blomgren, "The Development and Future of Lithium Ion Batteries," J. Electrochem. Soc., 164(1), A5019 (2017).

2. J. Graetz and F. Wang, Nanoscale Anodes of Silicon and Germanium for Lithium Batteries, Pan Stanford Publishing Stanford, 2013.

3. J. M. Paz-Garcia, O. O. Taiwo, E. Tudisco, D. P. Finegan, P. R. Shearing, D. J. L. Brett, and S. A. Hall, "4D analysis of the microstructural evolution of Sibased electrodes during lithiation: Time-lapse X-ray imaging and digital volume correlation," J. Power Sources, 320, 196 (2016)

4. C. K. Chan, M. T. McDowell, and Y. Cui, Silicon Nanowire Electrodes for LithiumIon Battery Negative Electrodes, Pan Stanford Publishing, Stanford, 2013.

5. N. Liu, Z. Lu, J. Zhao, M. T. McDowell, H.-W. Lee, W. Zhao, and Y. Cui, "A pomegranate-inspired nanoscale design for large-volume-change lithium battery anodes," Nat. Nanotech., 9(3), 187 (2014).

6. M. T. McDowell, S. W. Lee, W. D. Nix, and Y. Cui, "25th Anniversary Article: Understanding the Lithiation of Silicon and Other Alloying Anodes for Lithium-Ion Batteries," Adv. Mater., 25(36), 4966 (2013)

7. S. E. Trask, K. Z. Pupek, J. A. Gilbert, M. Klett, B. J. Polzin, A. N. Jansen, and D. P. Abraham, "Performance of Full Cells Containing Carbonate-Based LiFSI Electrolytes and Silicon-Graphite Negative Electrodes," J. Electrochem. Soc., 163(3), A345 (2016).

8. M. Klett, J. A. Gilbert, S. E. Trask, B. J. Polzin, A. N. Jansen, D. W. Dees, and D. P. Abraham, "Electrode Behavior RE-Visited: Monitoring Potential Windows, Capacity Loss, and Impedance Changes in Li1.03(Ni0.5Co0.2Mn0.3)0.97O2/SiliconGraphite Full Cells," J. Electrochem. Soc., 163(6), A875 (2016).

9. S. D. Beattie, M. J. Loveridge, M. J. Lain, S. Ferrari, B. J. Polzin, R. Bhagat, and R. Dashwood, "Understanding capacity fade in silicon based electrodes for lithiumion batteries using three electrode cells and upper cutoff voltage studies," J. Power Sources, 302, 426 (2016).

10. C. Fang, Y. Deng, Y. Xie, J. Su, and G. Chen, "Improving the Electrochemical Performance of Si Nanoparticle Anode Material by Synergistic Strategies of Polydopamine and Graphene Oxide Coatings," J. Phys. Chem. C, 119(4), 1720 (2015).

11. N. Delpuech, D. Mazouzi, N. Dupré, P. Moreau, M. Cerbelaud, J. S. Bridel, J. C. Badot, E. De Vito, D. Guyomard, B. Lestriez, and B. Humbert, "Critical Role of Silicon Nanoparticles Surface on Lithium Cell Electrochemical Performance Analyzed by FTIR, Raman, EELS, XPS, NMR, and BDS Spectroscopies," J. Phys. Chem. C, 118(31), 17318 (2014)

12. J. Xu, Q. Zhang, and Y.-T. Cheng, "High Capacity Silicon Electrodes with Nafion as Binders for Lithium-Ion Batteries," J. Electrochem. Soc., 163(3), A401 (2015).

13. T. Chen, Q. Zhang, J. Pan, J. Xu, Y. Liu, M. Al-Shroofy, and Y.-T. Cheng, "LowTemperature Treated Lignin as Both Binder and Conductive Additive for Silicon
Nanoparticle Composite Electrodes in Lithium-Ion Batteries," ACS Appl. Mater Interfaces, 8(47), 32341 (2016).

14. R. R. Garsuch, D.-B. Le, A. Garsuch, J. Li, S. Wang, A. Farooq, and J. R. Dahn, "Studies of Lithium-Exchanged Nafion as an Electrode Binder for Alloy Negatives in Lithium-Ion Batteries," J. Electrochem. Soc., 155(10), A721 (2008),

15. A. Magasinski, B. Zdyrko, I. Kovalenko, B. Hertzberg, R. Burtovyy, C. F. Huebner, T. F. Fuller, I. Luzinov, and G. Yushin, "Toward Efficient Binders for Li-Ion Battery Si-Based Anodes: Polyacrylic Acid," ACS Appl. Mater. Interfaces, 2(11), 3004 (2010).

16. N. S. Hochgatterer, M. R. Schweiger, S. Koller, P. R. Raimann, T. Wöhrle, C. Wurm, and M. Winter, "Silicon/Graphite Composite Electrodes for High-Capacity Anodes: Influence of Binder Chemistry on Cycling Stability," Electrochem. Solid-State Lett., 11(5), A76 (2008)

17. L. Wei, C. Chen, Z. Hou, and H. Wei, "Poly (acrylic acid sodium) grafted carboxymethyl cellulose as a high performance polymer binder for silicon anode in lithium ion batteries," Sci. Rep., 6, 19583 (2016).

18. C. C. Nguyen, T. Yoon, D. M. Seo, P. Guduru, and B. L. Lucht, "Systematic Investigation of Binders for Silicon Anodes: Interactions of Binder with Silicon Particles and Electrolytes and Effects of Binders on Solid Electrolyte Interphase Formation," ACS Appl. Mater. Interfaces, 8(19), 12211 (2016).

19. M. T. Jeena, J.-I. Lee, S. H. Kim, C. Kim, J.-Y. Kim, S. Park, and J.-H. Ryu, "Multifunctional Molecular Design as an Efficient Polymeric Binder for Silicon Anodes in Lithium-Ion Batteries," ACS Appl. Mater. Interfaces, 6(20), 18001 (2014).

20. B. Koo, H. Kim, Y. Cho, K. T. Lee, N.-S. Choi, and J. Cho, "A Highly Cross-Linked Polymeric Binder for High-Performance Silicon Negative Electrodes in Lithium Ion Batteries," Angew. Chem. Int. Ed., 51(35), 8762 (2012).

21. B. Liu, P. Soares, C. Checkles, Y. Zhao, and G. Yu, "Three-Dimensional Hierarchical Ternary Nanostructures for High-Performance Li-Ion Battery Anodes," Nano Lett. 13(7), 3414 (2013).

22. Q. Wang, R. Li, D. Yu, X. Zhou, J. Li, and Z. Lei, "Enhanced cycling stability of silicon anode by in situ polymerization of poly(aniline-co-pyrrole)," $R S C A d v .4(96)$, 54134 (2014).

23. H. Wu, G. Yu, L. Pan, N. Liu, M. T. McDowell, Z. Bao, and Y. Cui, "Stable Li-ion battery anodes by in-situ polymerization of conducting hydrogel to conformally coat silicon nanoparticles," Nat. Commun., 4, 1943 (2013).

24. X. Yu, H. Yang, H. Meng, Y. Sun, J. Zheng, D. Ma, and X. Xu, "Three-Dimensional Conductive Gel Network as an Effective Binder for High-Performance Si Electrodes in Lithium-Ion Batteries," ACS Appl. Mater. Interfaces, 7(29), 15961 (2015).

25. N. García, E. Benito, J. Guzmán, and P. Tiemblo, "Use of p-Toluenesulfonic Acid for the Controlled Grafting of Alkoxysilanes onto Silanol Containing Surfaces: Preparation of Tunable Hydrophilic, Hydrophobic, and Super-Hydrophobic Silica," J. Am. Chem. Soc., 129(16), 5052 (2007).

26. Y.-J. Wanglee, J. Hu, R. E. White, M.-Y. Lee, S. M. Stewart, P. Perrotin, and S. L. Scott, "Borane-Induced Dehydration of Silica and the Ensuing WaterCatalyzed Grafting of B(C6F5)3 To Give a Supported, Single-Site Lewis Acid, $\equiv$ SiOB(C6F5)2," J. Am. Chem. Soc., 134(1), 355 (2012).

27. M. T. Jeena, T. Bok, S. H. Kim, S. Park, J.-Y. Kim, S. Park, and J.-H. Ryu, "A siloxaneincorporated copolymer as an in situ cross-linkable binder for high performance silicon anodes in Li-ion batteries," Nanoscale, 8(17), 9245 (2016).

28. X. Li, D. Zhang, K. Xiang, and G. Huang, "Synthesis of polyborosiloxane and its reversible physical crosslinks," RSC Adv. 4(62), 32894 (2014).

29. N. Seetapan, A. Fuongfuchat, D. Sirikittikul, and N. Limparyoon, "Unimodal and bimodal networks of physically crosslinked polyborodimethylsiloxane: viscoelastic and equibiaxial extension behaviors," J. Polym. Res., 20(7), 183 (2013).

30. E. D'Elia, S. Barg, N. Ni, V. G. Rocha, and E. Saiz, "Self-Healing Graphene-Based Composites with Sensing Capabilities," Adv. Mater., 27(32), 4788 (2015).

31. H.-T. Chiu and J.-H. Wu, "Conductive effect of an electronic/ionic complex conductivity modifier for silicone elastomers," J. Appl. Polym. Sci., 97(3), 711 (2005).

32. R. Kurono, M. A. Mehta, T. Inoue, and T. Fujinami, "Preparation and characterization of lithium ion conducting borosiloxane polymer electrolytes," Electrochim. Acta, 47(3), 483 (2001)

33. J. Shim, D.-G. Kim, H. J. Kim, J. H. Lee, and J.-C. Lee, "Polymer Composite Electrolytes Having Core-Shell Silica Fillers with Anion-Trapping Boron Moiety in the Shell Layer for All-Solid-State Lithium-Ion Batteries," ACS Appl. Mater. Interfaces, 7(14), 7690 (2015).

34. Z. Liu, S. J. Picken, and N. A. M. Besseling, "Polyborosiloxanes (PBSs), Synthetic Kinetics, and Characterization," Macromol. 47(14), 4531 (2014).

35. T. Wu and B. Chen, "Synthesis of Multiwalled Carbon Nanotube-Reinforced Polyborosiloxane Nanocomposites with Mechanically Adaptive and Self-Healing Capabilities for Flexible Conductors," ACS Appl. Mater. Interfaces, 8(36), 24071 (2016). 